\title{
Pretreatment with corticosteroids attenuates the efficacy of colchicine in preventing recurrent pericarditis: a multi-centre all-case analysis
}

\author{
Galit Artom ${ }^{1}$, Nira Koren-Morag ${ }^{2}$, David H. Spodick ${ }^{3}$, Antonio Brucato ${ }^{4}$, \\ Joseph Guindo ${ }^{5}$, Antoni Bayes-de-Luna ${ }^{5}$, Giovanni Brambilla ${ }^{4}$, \\ Yaron Finkelstein ${ }^{1}$, Brigitte Granel ${ }^{6}$, Antoni Bayes-Genis ${ }^{5}$, \\ Ehud Schwammenthal ${ }^{1}$, and Yehuda Adler ${ }^{1 *}$ \\ ${ }^{1}$ Cardiac Rehabilitation Institute, Sheba Medical Centre, Tel-Hashomer 52621, Israel \\ ${ }^{2}$ Sackler school of Medicine, Tel Aviv University, Israel \\ ${ }^{3}$ St Vincent Hospital, Worchester, MA, USA \\ ${ }^{4}$ Department of Medicine Brera, Rheumatology, Niguarda Ca'Granda Hospital, Milan, Italy \\ ${ }^{5}$ Service of Cardiology, Hospital de la Santa Creu i Sant Pau, Barcelona, Spain \\ ${ }^{6}$ Service de Medicine Interne, Hopital de la Timone, Marseille, France
}

Received 12 April 2004; revised 8 January 2005; accepted 3 February 2005; online publish-ahead-of-print 8 March 2005

See page 631 for the editorial comment on this article (doi:10.1093/eurheartj/ehi045)

KEYWORDS

Pericarditis;

Corticosteroids;

Colchicine

\begin{abstract}
Aims Effective prevention of recurrent pericarditis remains an important yet elusive goal. Corticosteroid therapy often needs to be continued for a prolonged period and causes severe side effects. We performed a multi-centre all-case analysis to investigate the efficacy of colchicine in preventing subsequent relapses of pericarditis, and addressed the hypothesis that pretreatment with corticosteroids may attenuate the beneficial effect of colchicine.

Methods and results One hundred and forty published and unpublished cases of patients treated with colchicine after at least two relapses of pericarditis were aggregated from European centres. Of those, 119 were included in the study group. Only $18 \%$ of the patients had relapses under colchicine therapy, and $30 \%$ after its discontinuation. There were significantly more relapses among male patients after colchicine treatment ( 36 vs. $17 \%, P=0.046$ ), and those with previous corticosteroid treatment (43 vs. $13 \%, P=0.02$ ). Multivariate logistic regression analysis identified previous corticosteroid therapy (OR 6.68, 95\% Cl: 1.65-27.02) and male gender (OR $4.20,95 \% \mathrm{Cl}: 1.16-15.21$ ) as independent risk factors for recurrence following colchicine therapy.

Conclusion Treatment with colchicine is highly effective in preventing recurrent pericarditis, while pretreatment with corticosteroids exacerbates and extends the course of recurrent pericarditis.
\end{abstract}

\footnotetext{
* Corresponding author. Tel: 97258 547138; fax: 97235303079.

E-mail address: adlery@sheba.health.gov.il
} 


\section{Introduction}

Effective prevention of recurrent pericarditis remains an important yet elusive goal. ${ }^{1-3}$ Therapeutic approaches have traditionally included non-steroidal anti-inflammatory drugs (NSAIDs), corticosteroids, immunosuppressive agents, and, in unremitting cases, pericardiectomy. ${ }^{1-3}$ Because relapses may occur during attempts to reduce drug dose, corticosteroid therapy, once initiated, often needs to be continued for a prolonged period of time, and is therefore fraught with severe side effects. ${ }^{2-5}$ Moreover, clinical observations have raised the suspicion that corticosteroid use may actually prolong attacks and predispose to further recurrences. ${ }^{5}$ For the treatment of acute pericarditis the use of corticosteroids is recommended only as a last resort for severe resistant cases. ${ }^{6}$

Colchicine, a unique anti-inflammatory agent that was introduced for the therapy of acute gout in $1763,{ }^{7}$ provides dramatic relief from acute inflammatory attacks, in addition to acting as a prophylactic agent for the chronic pattern. ${ }^{7}$ It was first proposed for the treatment of recurrent pericarditis in 1987 by Rodriguez de La Serna et al., ${ }^{8}$ based on its proven efficacy to prevent relapses of polyserositis in familiar Mediterranean fever. In 1990, Guindo et al. ${ }^{9}$ published the first clinical study supporting the efficacy of colchicine in preventing recurrences of pericarditis. To date, several small nonrandomized studies and case reports have corroborated the efficacy and safety of colchicine in the management of recurrent pericarditis. ${ }^{10-25}$ In the absence of a randomized, placebo-controlled trial, as proposed by The Taskforce of Pericardial Disease of the World Heart Federation, ${ }^{26}$ we sought to aggregate all published and unpublished data available on the outcome of patients with recurrent pericarditis treated with colchicine. Employing this multi-centre all-case approach, a database of 119 cases was created. We then investigated the influence of predefined clinical variables on the efficacy of colchicine in preventing subsequent relapses of pericarditis in a multivariable logistic regression model. In particular, we addressed the hypothesis that pretreatment with corticosteroids may attenuate the beneficial effect of colchicine in patients with recurrent pericarditis.

\section{Methods}

The study was designed as a multi-centre all-case analysis. Researchers who published studies and case reports on colchicine treatment in recurrent pericarditis during the last 15 years were approached and asked to contribute all available cases to the database. Patient's data were obtained from Italy $(n=44)$, France $(n=37)$, Spain $(n=33)$, Israel $(n=20)$, Lebanon $(n=3)$, Turkey $(n=2)$, and Denmark $(n=1)$.

A total of 140 cases ( 99 patients from published studies and case reports, and 41 so far unpublished cases) were screened to match the following inclusion criteria:

(i) clinical diagnosis of two or more relapses of acute pericarditis;

(ii) therapeutic trial of colchicine beyond its use during the tapering period of corticosteroids or NSAID; (iii) complete documented follow-up since the first episode of acute pericarditis, including reports on therapeutic trials with corticosteroids, and continuing for at least 1 month following initiation of colchicine therapy.

In particular, data were considered complete only in patients with a methodical follow-up since first relapse of pericarditis, that included precise information about the following predefined clinically relevant variables: age, sex, etiology of pericarditis, duration of follow-up since first relapse of pericarditis, use of corticosteroid therapy, number or relapses before initiation of colchicine treatment, and duration of colchicine treatment, and duration of follow-up after discontinuation of colchicine treatment. In addition, precise information needed to be documented about the number of relapses during colchicine treatment as well as during follow-up after discontinuation of colchicine treatment (post-colchicine).

Twenty-one patients had to be excluded, 13 patients were lacking definitive age data, 6 patients were treated with a colchicine dose different from $1 \mathrm{mg} /$ day for a prolonged period (to achieve homogeneity of treatment), and 2 patients had been followed-up for $<1$ month; no patient was reported dead. The remaining 119 patients represent the study group, 78 of whom were male $(65 \%)$ and 41 were female $(35 \%)$, ranging in age from 8 to 83 years ( $44 \pm 18$ years).

Follow-up from the instituting of colchicine therapy ranged from 1 to 185 months. In 88 patients (74\%), colchicine therapy was discontinued during follow-up and renewed only in case of relapse. In these patients, the total length of treatment was summed up for analysis. Thirty-one patients (26\%) were taking colchicine as a permanent treatment and no colchicine-free follow-up was documented; in four patients (3.4\%) follow-up after colchicine treatment lasted for only 1 month.

\section{Statistical methods}

Results were expressed as mean value \pm SD. Comparison between groups was performed by $\chi^{2}$ test or Fisher's exact test for categorical variables and by $t$-test for continuous variables. The predefined clinically variables were tested for correlation, by Pearson correlation, with the number of relapses after colchicine therapy. Variables, for which a significant relationship was found, were then entered into a multivariable logistic regression analysis (forward likelihood ratio) to identify independent risk factors for relapses. The statistical model derived was validated using the Hosmer-Lemeshow test yielding a test statistics of $6.56, P=0.585$. Results were expressed as OR and $95 \%$ $\mathrm{Cl}$. $P$-value $<0.05$ was considered significant.

\section{Results}

While all patients had experienced recurrences before treatment with colchicine, only $18 \%$ of patients $(21 / 119)$ had relapses during colchicine treatment, and 30\% (26/ 88) after its discontinuation. Relapses occurred significantly more among men than women (36 vs. $17 \%$, $P=0.058)$ after discontinuation of colchicine therapy (Figure 1). Corticosteroids were administered to $60 \%$ of patients prior to initiation of colchicine treatment. The percentage of patients with relapses before, during, and after colchicine treatment in the respective groups is presented in Figure 2. In patients with previous corticosteroid treatment, a significantly higher number of patients had recurrence after colchicine treatment (43 vs. $13 \%$, $P=0.02$ ). Comparing the data for those treated with 


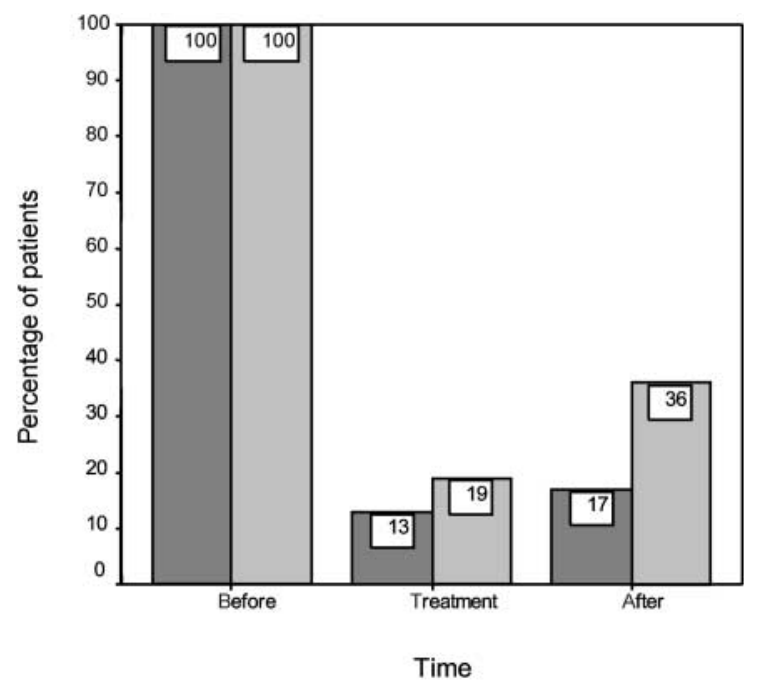

Figure 1 Gender difference in the percentage of patients with relapse during the treatment with colchicine and after its discontinuation. Dark grey, female; light grey, male.

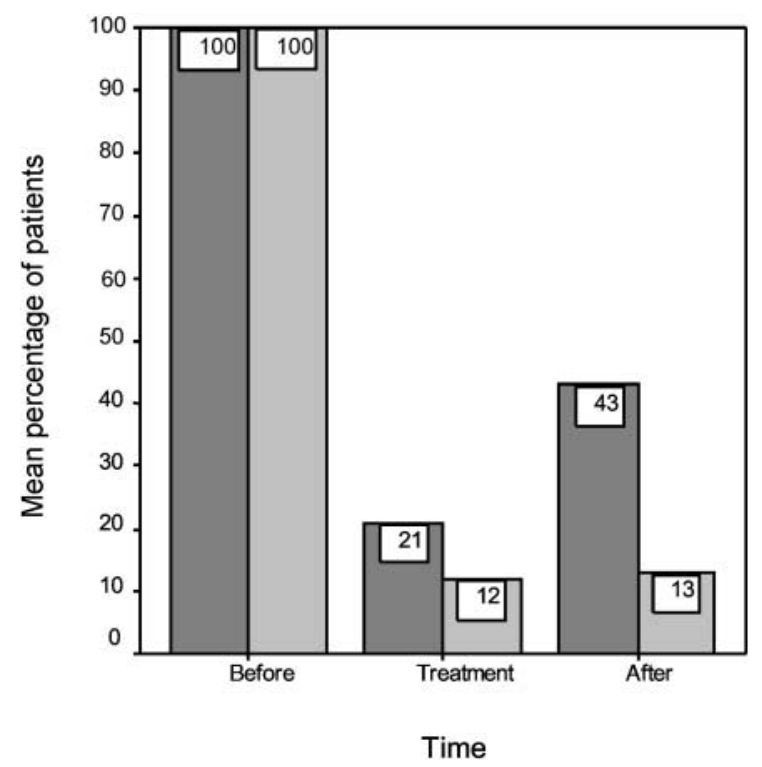

Figure 2 Differences in the percentage of patients with relapses during the treatment with colchicine and after its discontinuation as a function of a previous corticosteroid treatment. Dark grey, with corticosteroids; light grey, without corticosteroids.

and without corticosteroids (Table 1 ) reveals that the duration of colchicine treatment was significantly longer $(24.4 \pm 23.3$ vs. $9.7 \pm 7.8, P=0.001)$, and the average number of relapses per patient after colchicine treatment was significantly higher $(0.65 \pm 0.99$ vs. $0.18 \pm 0.56$, $P=0.006$ ) among those with previous corticosteroid treatment. No differences were found between the two groups regarding the average number of relapses per patient during colchicine treatment. Table 2 details the partial correlations between the number of relapses in each period and the duration of follow-ups and treatment, controlling for age.
As expected, there was a significant correlation between duration of follow-up and number of relapses before colchicine treatment $(r=0.63, P<0.01)$. No correlation was found between duration of colchicine treatment and number of relapses before colchicine treatment. There was no correlation between the numbers of relapses in each period of follow-up; in particular, there was no correlation between the numbers of relapses before colchicine treatment and the number of relapses under colchicine treatment, or after its discontinuation.

When entering the five variables for which a significant correlation with the number of relapses after colchicine therapy was found-age, gender, previous corticosteroid therapy, duration of treatment, and follow-up into a multivariable logistic regression analysis, only corticosteroid and male gender treatment emerged as independent predictors for recurrences (Table 3 ). The OR for previous corticosteroid therapy was $6.68(95 \% \mathrm{Cl}$ : $1.65-27.02$, $P=0.008)$ and for male gender $4.2 \quad(95 \% \mathrm{Cl}$ : 1.16-15.21, $P=0.029)$.

In almost $70 \%$ of the patients, no specific etiology of pericarditis could be identified. The other etiologies were identified as s/p pericardiectomy (16\%), s/p myocardial infarct (7.6\%), familial Mediterranean fever (3.4\%), systemic lupus erythematosus $(1.7 \%)$, rheumatoid arthritis $(0.8 \%)$, and sjogren's syndrome $(0.8 \%)$. A viral infection was confirmed only in two patients (1.7\%).

\section{Discussion}

The present multi-centre all-case analysis of the largest database so far demonstrates that colchicine therapy is highly effective in preventing recurrences of acute pericarditis. The results are particularly encouraging, because the study included only patients with at least two previous relapses, thus focusing on a group that represents a major therapeutic challenge. As hypothesized, the proportion of patients with relapses during or after colchicine therapy was significantly higher in the group of patients treated with corticosteroids in the past. Moreover, duration of colchicine therapy was significantly longer $(P=0.001)$ in patients pretreated with corticosteroids (24.5 months) than in those who were not $(9.7$ months). Although these patients had significantly more relapses before institution of colchicine therapy than patients who had not received corticosteroids in the past (Table 1), the question arises whether past corticosteroid use may be simply a marker of a higher tendency to relapse, rather than a cause of it.

However, the lack of correlation between the number of relapses before colchicine therapy and the number of relapses during, or following colchicine therapy (Table 2 ) supports the view that corticosteroid therapy itself is associated with a higher tendency to relapse. In fact, logistic multivariable analysis identified pretreatment with steroids as the most powerful independent predictor of relapse following colchicine therapy, carrying an almost seven-fold increased risk (OR 6.68, $P=0.008)$ on average (Table 3$)$. The second independent predictor of relapse was male gender (OR 4.2, $P=0.029)$. 
Table 1 Comparison between the number of relapses, duration of follow-up, and colchicine treatment in patients with and without previous corticosteroid treatments

\begin{tabular}{|c|c|c|c|c|c|c|c|c|}
\hline & \multicolumn{3}{|c|}{$\begin{array}{l}\text { Corticosteroid } \\
\text { treatment }\end{array}$} & \multicolumn{3}{|c|}{$\begin{array}{l}\text { No corticosteroid } \\
\text { treatment }\end{array}$} & \multirow[t]{2}{*}{$T$} & \multirow[t]{2}{*}{$P$-value } \\
\hline & $n$ & Mean & SD & $n$ & Mean & SD & & \\
\hline Follow-up before colchicine treatment (in months) & 71 & 19.3 & 33.9 & 48 & 14.2 & 29.9 & 0.85 & 0.396 \\
\hline $\begin{array}{l}\text { No. of relapses per patient before treatment } \\
\text { (including first episode) }\end{array}$ & 71 & 5.10 & 5.70 & 48 & 2.81 & 1.02 & 3.30 & 0.001 \\
\hline Treatment with colchicine (in months) & 71 & 24.5 & 23.3 & 48 & 9.7 & 7.8 & 4.50 & 0.001 \\
\hline No. of relapses per patient under colchicine & 71 & 0.46 & 1.45 & 48 & 0.19 & 0.53 & 1.47 & 0.145 \\
\hline Follow-up post colchicine (in months) & 49 & 47.6 & 39.1 & 39 & 26.1 & 18.9 & 3.35 & 0.001 \\
\hline No. of relapses per patient post colchicine & 49 & 0.65 & 0.99 & 39 & 0.18 & 0.56 & 2.83 & 0.006 \\
\hline
\end{tabular}

Table 2 Partial correlation between the number of relapses per patient and duration of follow-up and treatment, controlling for age

\begin{tabular}{|c|c|c|c|c|c|c|}
\hline & $\begin{array}{l}\text { Duration of } \\
\text { follow-up } \\
\text { before }\end{array}$ & $\begin{array}{l}\text { No. of } \\
\text { relapses } \\
\text { before }\end{array}$ & $\begin{array}{l}\text { Duration of } \\
\text { treatment }\end{array}$ & $\begin{array}{l}\text { No. of } \\
\text { relapses } \\
\text { during }\end{array}$ & $\begin{array}{l}\text { Duration of } \\
\text { follow-up } \\
\text { post }\end{array}$ & $\begin{array}{l}\text { No. of } \\
\text { relapses } \\
\text { post }\end{array}$ \\
\hline Duration of follow-up before colchicine & 1 & $0.63^{*}$ & 0.07 & -0.01 & 0.18 & 0.16 \\
\hline No. of relapses per patient before & & 1 & 0.14 & 0.11 & 0.22 & 0.08 \\
\hline Duration of treatment with colchicine & & & 1 & 0.20 & -0.16 & 0.06 \\
\hline No. of relapses per patient during colchicine & & & & 1 & -0.06 & -0.03 \\
\hline Duration of follow-up post colchicine & & & & & 1 & 0.17 \\
\hline No. of relapses post colchicine & & & & & & 1 \\
\hline
\end{tabular}

$* P<0.01$

Table 3 Logistic regression for predicted relapses after colchicine treatment

\begin{tabular}{llll}
\hline Variable & OR & $95 \%$ C.I. & $P$-value \\
\hline Male gender & 4.20 & $1.16-15.21$ & 0.029 \\
Age (5 years) & 0.90 & $0.76-1.11$ & 0.237 \\
$\begin{array}{l}\text { Previous corticosteroids } \\
\text { treatment }\end{array}$ & 6.68 & $1.65-27.02$ & 0.008 \\
$\begin{array}{l}\text { Treatment duration } \\
\quad(6 \text { months) }\end{array}$ & 1.13 & $0.91-1.39$ & 0.278 \\
$\begin{array}{l}\text { Follow-up after colchicines } \\
\quad \text { treatment (3 months) }\end{array}$ & 0.96 & $0.91-1.01$ & 0.174 \\
\hline
\end{tabular}

The fact that most of the patients studied were from Mediterranean countries gives rise to the question of whether recurrent pericarditis occurred as a symptom of familiar Mediterranean fever. ${ }^{27,28}$ However, only four patients $(3.4 \%)$ were diagnosed with this disease, while pericarditis was considered idiopathic in almost $70 \%$ of the study group. A further investigation of the idiopathic cases would presumably reveal either viral or autoimmune etiologies. ${ }^{29,30}$

While all patients showed relief of signs and symptoms under colchicine therapy, 18\% (21/119) of the patients had new relapses under colchicine treatment. Considering the natural course of the disease, characterized by periodic relapses, ${ }^{3}$ it might have been expected that patients would experience new recurrences after discontinuation of the therapy. However, during a mean follow-up period of over 2 years, $70 \%$ of the patients $(62 / 88)$ in whom colchicine was discontinued remained free from new relapses. The absence of a correlation between the number of relapses per patient in the different periods of follow-up (before, during, and post colchicine) supports the concept that colchicine therapy provides sustained benefit even after discontinuation of the drug.

\section{Study limitations}

The present study is an analysis of patients with recurrent pericarditis with substantial variation in the number of previous relapses (from 2 to 45 episodes), the timing of instituting colchicine therapy (from 1 to 228 months following the first episode) as well as treatment duration (from 1 to 128 months, with $26 \%$ of the patients receiving colchicine permanently). On the other hand, such variation represents the full spectrum of clinically relevant presentations of recurrent pericarditis. In order to approach homogeneity with respect to the treatment protocol, only patients who were treated with a conventional dose of $1 \mathrm{mg}$ of colchicine per day, which combines high efficacy with a low prevalence of side effects, ${ }^{8-9}$ were included in the analysis. Every 
attempt was made to include unpublished cases in this multi-centre all-case analysis to avoid publication bias, yet by its very nature this is difficult to ascertain completely.

Ultimately, only a randomized placebo-controlled double-blind trial may provide a definitive answer to the question of optimal therapy for recurrent pericarditis. However, in the absence of such a study, the analysis of the present large database provides an important source of information for guiding the treatment of this problematic patient group.

\section{Conclusions}

Pretreatment with corticosteroids attenuates the efficacy of colchicine in preventing recurrent pericarditis, exacerbating and extending its course. Colchicine is highly effective in preventing new relapses in patients with recurrent pericarditis. Because of the increased risk of recurrences and the severe side effects of prolonged corticosteroids therapy on one hand, and the favourable efficacy and the few side effects of colchicine on the other hand, we consider colchicine in a dose of $1 \mathrm{mg} /$ day as the first-line drug of choice for recurrent pericarditis.

\section{Acknowledgements}

We want to thank our fellow researchers for contributing important patients: Dr Ercan Tutar from the Department of Pediatric Cardiology, Ankara University Medical School, Turkey; Dr Giuseppe Sforza from the Dipartemento di Cardiologia, Ospedale 'immacolata Concezione', Padova, Italy; and $\mathrm{Dr}$ Søren Madsen from the Department of Haermatology, Finsen Centre, Rigshospitalet, Denmark. The work was done in the Cardiac Rehabilitation Institute, Sheba Medical Centre, Tel-Hashomer, Israel.

\section{References}

1. Adler Y, Zandman-Goddard G, Ravid M, Avidan B, Zemer D, Ehrenfeld M, Shemesh J, Tomer Y, Shoenfeld Y. Usefulness of colchicine in preventing recurrences of pericarditis. Am J Cardiol 1994;73:916-917.

2. Maning WJ. Diseases of the pericardium. In: Cecil LC, Bennet JC, Goldman L, eds. Cecil Textbook of Medicine. 20th ed. Philadelphia, PA: WB Saunders; 1996. p336-342.

3. Spodick DH. Pericardial diseases. In: Braunwald E, Zipes DP, Libby P, eds. Heart Disease. 6th ed. Philadelphia, PA: WB Saunders \& Co; 2001. p1823-1866.

4. Adolph RJ. Old drugs with new uses. Colchicine for the treatment of recurrent pericarditis [Editorial comment]. Circulation 1990;82: 1505-1506.

5. Fowler NO. Recurrent pericarditis. Cardiol Clin 1990;8:621-626.

6. Mewar SH, Shamsi SN, Anjur-Kapali N, Spodick DH. Acute pericarditis. Curr Treat Options Cardiovasc Med 1999;1:73-77.

7. Roberts LJ, Morrow JD. Analgesic, antipyretic \& antiinflammatory agents \& drugs employed in the treatment of gout. In: Hardman JG.
Limbird LE, eds. Goodman \& Gilman's The Pharmacological Basis of Therapeutics. 10th ed. Newyork, NY: McGraw-Hill; 2001. 719-720.

8. Rodriguez de la Serna A, Guindo J, Marti Claramunt V, Bayes de Luna A. Colchicine for recurrent pericarditis. (Letter). Lancet 1987;2:1517.

9. Guindo J, Rodriguez de la Serna A, Ramio J, de Miguel Diaz MA, Subirana MT, Perez Ayuso MJ, Cosin J, Bayes de Luna A. Recurrent pericarditis, relief with colchicine. Circulation 1990;82:1117-1120.

10. Adler $Y$, Finkelstein $Y$, Guindo J, Rodriguez de la Serna A, Shoenfeld $Y$, Sagie A, Bayes de Luna A, Spodick DH. Colchicine treatment for recurrent pericarditis. A decade of experience. Circulation 1998; 97:2183-2185.

11. Brucato A, Cimaz R, Balla E. Prevention of recurrences of corticosteroid-dependent idiopathic pericarditis by colchicine in an adolescent patient. Pediatr Cardiol 2000;21:395-396.

12. Granel B, Serratrice J, Rey J, Pache X, Swiader L, Habib G, Mesana T, Ene N, Disdier P, Weiller PJ. Is chronic or recurrent idiopathic pericarditis an autonomous inflammatory disease? Rev Med Intern 2001; 22:1204-1212.

13. Millaire A, de Groote P, Decoulx E, Goullard L, Ducloux G. Treatment of recurrent pericarditis with colchicines. Eur Heart J 1994;15: 120-124.

14. Cacoub P, Sbai A, Wechsler B, Amoura Z, Godeau P, Piette JC. Efficacy of colchicine in recurrent acute idiopathic pericarditis. Arch Mal Coeur 2000;93:1511-1154.

15. Douchet MP, Attali P, Fincker JL. A case of recurrent benign pericarditis treated by colchicine. Eur Heart J 1993;14:431-432.

16. Tutar HE, Imamoglu A, Atalay S. Recurrent pericarditis in familial Mediterranean fever. (Letter). Acta Paediatr 1999;88:1045-1046.

17. Tauber T, Zimand S, Kotzer E. Recurrent pericarditis in familial Mediterranean fever. Harefuah 1995;128:611-612.

18. Grande Ingelmo JM, Hernandez Osegueda M, Kallmeyer Martin C Barroso Lopez JL, Lopez Bescos L. Recurrent pericarditis: our experience with colchicines. Rev Esp Cardiol 1995;48:765-767.

19. Sforza G, Targa L, Resta M, Vaglio A, Martines M, Martines C. Colchicine in the treatment of idiopathic pericarditis. Report of a case. Minerva Cardioangiol 1995; 43: 281-285.

20. Madsen SM, Jackobsen TJ. Colchicine treatment of recurrent steroid dependent pericarditis in a patient with post-myocardial-infarction syndrome (Dressler's syndrome). Ugeskr Laeger 1992;154:3427-3428.

21. Yazigi A, Abou-Charaf LC. Colchicine for recurrent pericarditis in children. Acta Paediatr 1998;87:603-604.

22. Adler Y, Shoenfeld Y. Colchicine as therapy for recurrent pericarditis. Harefuah 1997;133:100-102.

23. Adler Y, Aharon A, Zandman-Goddard G. Relief of recurrent pericarditis by colchicine. Harefuah 1994;126:248-249.

24. Adler $\mathrm{Y}$, Finkelstein $\mathrm{Y}$, Amir J. Recurrent episodes of pericarditis coincide with discontinuation of colchicine therapy. $J$ Noninvasive Cardiol 1999;3:65-66.

25. Adler Y, Guindo J, Finkelstein Y, Khouri A, Assali A, Bayes-Genis A, Bayes de Luna A. Colchicine for large pericardial effusions. Clin Cardiol 1998;21:143-144.

26. Maisch B, Ristic AD, Seferovic PM. New directions in diagnosis and treatment of pericardial disease. A project of the Taskforce on Pericardial Disease of the World Heart Federation. Herz 2000;25: 769-780.

27. Adler Y, Finkelstein Y, Guindo J, Rodriguez de La Serna A, Beyes-Genis A, Bayes De Luna A, Shoenfeld Y, Sagie A, Spodick DH. Recurrent pericarditis as a manifestation of familial Mediterranean fever. London and Tel Aviv: (Letter). Circulation 2000;101:E71-E72.

28. Adler Y, Finkelstein Y, Spodick DH. Colchicine for pericardial diseases. In: Sohar E, Gafni J, Pras M, eds. Familial Mediterranean Fever. London and Tel Aviv: Freud Publishing House; 1997. p31-35.

29. Maisch B, Ristic AD. Practical aspects of the management of pericardial disease. Heart 2003;89:1096-1103.

30. Spodick DH. Acute pericarditis: current concepts and practice. JAMA 2003;289:1150-1153. 